\title{
Strategi Pembelajaran Guru dalam Mengajarkan Materi Fiqih Bersifat Khilafiyah
}

\author{
Novia Susanti ${ }^{1}$, Murniyetti ${ }^{2}$ \\ Jurusan Ilmu Agama Islam, Fakultas Ilmu Sosial, Universitas Negeri Padang, Indonesia ${ }^{1,2}$ \\ snovia049@gmail.com¹, murniyetti@fis.unp.ac.id ${ }^{2}$
}

\begin{abstract}
This study aims to find out what material in fiqih subjects are khilafiyah, the learning strategies of fiqih teachers in teaching fiqih material that are khilafiyah and see what obstacles are faced by fiqih teachers in teaching fiqih materials that are khilafiyah. The type of research that the author uses is field research (field research), while the research method that the author uses is a qualitative method with a descriptive approach. Sources of data were taken from nineteen informants consisting of teachers, madrasah leader, curriculum representatives and studens. To strengthen the research data, the writer also took observation and documentation data. All interview data were analyized by collecting, reducing, presenting and ending with conclution. Overall, the results of this study indicate that the fiqih that is khilafiyah is studied, namely about zakat on mining goods and rika (invented goods), nisab (minuman amount) of stolen goods, had (punishments) stealing, had (punishments) robbers. Robbers and pirates and insurance law in Islam, while the learning strategies of fiqih teachers in teaching fiqih material that is khilafiyah uses direct learning strategies. Obstacles faced by fiqih teachers in teaching fiqih material that are khilafiyah are the first, the level of intelligence of the studens who easily absorv learning some are less able to build understanding of the studens. Third, facilities and infrastructure, especially in learning media, are stiil limited so that teachers only uses simple and less varied learning methods.
\end{abstract}

Keywords: Fiqih Learning Strategies, Fiqih, Khilafiyah

\section{Pendahuluan}

Berbicara tentang strategi pembelajaran artinya sedang melakukan kajian terhadap dunia pendidikan, para ahli seperti Fakhrurrazi 2018 mengungkapkan bahwa dalam proses pembelajaran ada serangkaian pelaksanaan atas dasar hubungan timbal balik yang berlangsung secara edukatif untuk mencapai tujuan tertentu, oleh karena itu hubungan timbal balik antara guru dengan peserta didik merupakan bagian yang sangat penting dari proses tercapainya tujuan pendidikan. Jika pada proses pembelajaran terjadi ketimpangan antara guru dengan peserta didik maka besar kemungkinan efektifitas belajar tidak akan tercapai.

Pane \& Darwis Dasopang, 2017 berpendapat bahwa aktifitas belajar adalah suatu kegiatan yang dilakukan secara sadar dan disengaja dengan adanya usaha untuk melakukan perubahan pada diri peserta didik. Salah satu komponen penentu keberhasilan peserta didik dalam belajar adalah kepahaman peserta didik terhadap 

materi yang di ajarkan guru (Sardiyanah, 2020). Pahamnya peserta didik terhadap materi yang di ajarkan guru bagian penting untuk mencapai tujuan pembelajaran, agar tujuan pembelajaran tercapai secara optimal penting bagi pendidik untuk mengelola pembelajaran secara efektif dan efisien (Nasution, 2017).

Terkait isu yang penulis angkat dalam penelitian ini, ditemukan banyaknya alumni santri yang belum paham tentang materi fiqih yang bersifat khilafiyah, lazimnya sekolah-sekolah yang berbasis Islam seperti MTS, MAN, MTI dan Pondok Pesantren pasti mendalami mata pelajaran fiqih khususnya materi fiqih yang bersifat khilafiyah, sebagai santri dan alumni dari sekolah berbasis Islam sudah sewajarnya mampu menguasai problematika fiqih khilafiyah, pembahasan serta penyelesaiannya. Menurut hemat penulis output dari efektif atau tidaknya pembelajaran dapat dilihat melalui paham atau tidaknya para santri terhadap apa yang mereka dalami selama proses pembelajaran, berbicara tentang paham atau tidaknya para santri terhadap materi pembelajaran erat kaitannya dengan strategi pembelajaran. Nata, 2014 mengungkapkan bahwa strategi pembelajaran menjadi penentu keberhasilan dari proses pembelajaran.

Jika dianalisis fenomena yang terjadi, maka akan memunculkan berbagai pertanyaan besar seperti materi apakah dalam mata pelajaran fiqih bersifat khilafiyah? bagaimana strategi pembelajaran guru dalam mengajarkan materi fiqih bersifat khilafiyah? dan apa kendala yang dihadapi guru dalam mengajarkan materi fiqih bersifat khilafiyah?

\section{Tinjauan Pustaka}

Berdasarkan latar belakang yang penulis kemukakan sebelumnya, agar proses pembelajaran dapat dikelola secara efektif dan efisien maka seorang pendidik membutuhkan pengetahuan tentang strategi pembelajaran, oleh karena itu dalam standar pendidikan nasional disebutkan salah satu kompetensi yang harus dimiliki oleh seorang pendidik adalah kompetensi pedagogik yaitu kemampuan pendidik dalam mengelola pembelajaran secara efektif dan efisien (Nasution, 2017). Menurut Maslihan, 2019 dan Fatimah \& Sari, 2018 strategi pembelajaran dapat dikatakan sebagai rangkaian rencana pembelajaran yang di dalamnya terdapat penerapan metode, model serta teknik pembelajaran secara spesifik. Strategi pembelajaran berfungsi sebagai pendekatan dalam mengelola isi dan proses pembelajaran secara komprehensif untuk mencapai tujuan pembelajaran (Sapuadi, 2019: 3).

Salamah 2010: 9-12 mengungkapkan ada beberapa macam strategi pembelajaran yang diterapkan dalam dunia pendidikan seperti strategi pembelajaran langsung, strategi pembelajaran tidak langsung, strategi pembelajaran interaktif, strategi pembelajaran pengalaman, strategi pembelajaran mandiri, strategi pembelajaran ekspositori, dan strategi pembelajaran kooperatif .

Terkait dengan isu yang penulis angkat dalam penelitian ini, ditemukan banyaknya alumni santri yang belum paham tentang materi fiqih yang bersifat khilafiyah. Sedikit penulis ulas tentang fiqih khilafiyah, khilafiyah atau Ikhtilaf berasal dari bahasa Arab yakni خلف - يخلف - خلفان maknanya lebih umum dari adhdidhu, sebab setiap yang berlawanan (adhdidain) pasti akan saling bertentangan (Nanang Abdillah, 2016). Fiqih secara bahasa berarti فقير - يفق - فقبان yang artinya mengerti dan 
memahami Gharbal (dalam Nurhayati, dkk. 2018: 1). Syarifuddin dalam Nurhayati, dkk. 2018: 2 mengungkapkan bahwa fiqih dapat dikatakan sebagai ilmu yang mempelajari tentang hukum-hukum syara' yang berkaitan dengan amaliah orang yang mukallaf. Zahid, 2016 mengungkapkan bahwa penyebab terjadinya ikhtilaf ada lima poin. Pertama, adanya dalil kebolehan berijtihad. Kedua, keberagaman pemahaman ayat-ayat yang sifatnya zhanniyat. Ketiga, perbedaan dalam memahami hadist, Keempat, perbedaan dalam penetapan kaedah ushuliyah. Kelima, faktor diri dan lingkungan mujtahid. Menurut pendapat Jamrah penyebab terjadinya ikhtilaf yaitu ikhtilaf dalam qiraat, ikhtilaf ash sahabah dalam memahami hadist, adanya nash AlQur'an yang memiliki makna ganda, adanya nash yang terlihat seolah-olah saling bertentangan (taarudh), ada sebagian kasus yang tidak memiliki penjelasan dalam nash secara sharih.

Dari paparan di atas seorang pendidik memerlukan pengetahuan tentang strategi pembelajaran. Strategi pembelajaran berfungsi sebagai salah satu cara tercapainya tujuan pembelajaran secara optimal (Halimah, dkk, 2019: 190).

\section{Metodologi Penelitian}

Jenis penelitian yang penulis gunakan adalah field research (penelitian lapangan) sedangkan metode penelitian yang penulis gunakan adalah metode kualitatif dengan pendekatan deskriptif (Gunawan, 2013: 1-2). Penelitian ini merupakan kegiatan ilmiah terencana, terstruktur dan sitematis (Raco, 2010: 5). Sumber data diambil menggunakan teknik snowball sampling (Nurdiani, 2014). Sumber data penulis terdiri dari sembilan belas informan yang terdiri dari guru, pimpinan Madrasah, wakil kurikulum dan santri, sembilan belas informan tersebut terdiri dari dua orang guru fiqih, dua orang pimpinan Madrasah, satu orang wakil kurikulum dan lima belas orang santri selanjutnya sebagai bukti penulis menjalankan terkait dengan isu dan permasalahan yang dikaji maka penulis juga mengabadikan seluruh kegiatan yang dilakukan seperti wawancara langsung dengan informan, aktifitas belajar peserta didik dan cara guru mengajar materi fiqih yang bersifat khilafiyah. Untuk memperkuat data penelitian, penulis juga mengambil data observasi (Hasanah, 2017). Data hasil wawancara dianalisis dengan menggunakan model Miles dan Huberman berdasarkan penjelasan Rijali, 2019, Ahmad \& Nasution, 2018, dan Nilamsari, 2013: 31 dimulai dari pengumpulan data, reduksi data, penyajian data dan diakhiri dengan pengambilan kesimpulan.

\section{Hasil Penelitian dan Pembahasan}

Berdasarkan hasil wawancara yang dilakukan kepada sembilan belas informan penelitian, hasil analisis secara nyata mendapati enam materi fiqih bersifat khilafiyah yang dipelajari, enam materi fiqih bersifat khilafiyah yang dipelajari dapat dilihat melalui tabel 1 berikut. 


\section{Tabel 1}

\section{Materi Fiqih yang Bersifat Khilafiyah}

\begin{tabular}{clccc}
\hline No. & \multicolumn{1}{c}{ Materi } & Kelas & Semester \\
\hline 1. & Zakat barang tambang dan temuan (rikaz) & X & Ganjil \\
\hline 2. & Had mencuri & XI & Ganjil \\
3. & Nisab barang yang dicuri & XI & Ganjil \\
\hline 4. & Had meminum khamar & XI & Ganjil \\
\hline 5. & Had perampok, penyamun dan perompak & XI & Ganjil \\
6. & Hukum asuransi dalam Islam & XII & Ganjil \\
\hline
\end{tabular}

Berdasarkan tabel 1, dapat penulis jelaskan bahwa setelah diadakan wawancara mendalam dengan informan dan diperkuat dengan hasil observasi maka terdapat enam materi fiqih yang bersifat khilafiyah yang dipelajari. Enam materi tersebut iyalah 1) zakat barang tambang dan rikaz (barang temuan), 2) nisab (jumlah minimal) barang yang dicuri, 3) had (hukuman-hukuman) mencuri, 4) had (hukuman-hukuman) meminum khamar, 5) had (hukuman-hukuman) perampok, penyamun dan perompak, 6) hukum asuransi dalam Islam. Agar lebih menarik berikut ini penulis deskripsikan kutipan hasil wawancara dengan informan sebagaimana telah dijelaskan di atas. Adapun tampilan kutipan wawancara dengan informan adalah kutipan wawancara singkat.

\section{Tabel 2}

\section{Petikan Wawancara Materi Fiqih Bersifat Khilafiyah}

\begin{tabular}{lcl}
\hline \multicolumn{1}{c}{ Tema } & Informan & \multicolumn{1}{c}{ Petikan Wawancara } \\
\hline $\begin{array}{l}\text { Materi fiqih yang } \\
\text { bersifat } \text { khilafiyah }\end{array}$ & 4 & $\begin{array}{l}\text { Materi-materi fiqih yang bersifat khilafiyah yang di } \\
\text { ajarkan yakni tentang zakat barang tambang dan temuan } \\
\end{array}$ \\
& $\begin{array}{l}\text { (rikaz), nisab barang yang dicuri, had mencuri, had } \\
\text { meminum khamar, had perampok, penyamun dan } \\
\text { perompak dan hukum asuransi dalam Islam }\end{array}$ \\
\hline
\end{tabular}

Pada penguasaan materi pembelajaran guru harus memiliki wawasan luas sedangkan dalam hal praktik guru harus mampu menguasai peserta didik (Darmawiyah, 2017). Berdasarkan hasil observasi strategi pembelajaran yang digunakan guru mengajarkan materi fiqih yang bersifat khilafiyah menggunakan strategi pembelajaran langsung. Strategi pembelajaran adalah proses kegiatan belajar-mengajar yang dilakukan secara langsung, strategi pembelajaran ini lebih menekankan pada kemampuan guru sehingga menuntut guru agar lebih aktif dari pada peserta didik (Salamah, 2010: 9-12). Adapun gambaran strategi pembelajaran langsung yang digunakan guru mengajarkan materi fiqih bersifat khilafiyah adalah sebagai berikut:

\section{a. Pendahuluan}

1) Guru masuk kelas dengan mengucapkan salam; 
2) Membaca doa;

3) Membaca Al-qur'an bagi santri yang mendapat giliran.;

4) Guru memeriksa kehadiran;

5) Apersepsi.

\section{b. Kegiatan Inti}

1) Guru mendiktekan materi yang dipelajari hari itu;

2) Para santri mencatat materi yang didiktekan guru;

3) Guru menuliskan poin-poin materi di depan kelas;

4) Guru menjelaskan materi;

5) Guru memberikan kesempatan para santri untuk bertanya.

c. Penutup

1) Guru menyimpulkan materi;

2) Guru menyampaikan pesan diakhir pembelajaran;

3) Guru mengucapkan salam.

Selanjutnya kendala guru fiqih dalam mengajarkan materi fiqih bersifat khilafiyah pertama, sarana dan prasarana dalam media pembelajaran yang kurang memadai sehingga guru fiqih hanya menerapkan strategi pembelajarannya kurang bervariasi. Jannah \& Sontani, 2018: 56 menjelaskan bahwa banyak faktor yang mempengaruhi siswa dalam belajar salah satunya sarana dan prasarana. Sarana dan prasarana dapat mendorong siswa memiliki keinginan belajar yang lebih baik, menyenangkan dan memudahkan mereka dalam memahami pelajaran yang disampaikan oleh pendidik.

Kendala kedua yang di hadapi guru fiqih dalam mengajarkan materi fiqih bersifat khilafiyah, guru fiqih kurang mampu membangun pendapat para santri dalam memahami persoalan-persoalan khilafiyah fiqih. Darmawiyah, 2017 mengungkapkan bahwa seorang pendidik atau guru dalam proses pembelajaran dituntut tidak hanya memiliki kompetensi dalam bidang teoritik tetapi juga harus berkompetensi dalam bidang praktik. Jika dihubungkan pada penguasaan materi pembelajaran tentulah seorang guru harus memiliki wawasan luas dalam mata pelajaran yang dipegangnya serta mampu menghubungkan dengan mata pelajaran lainnya, sedangkan jika dihubungkan dengan kemampuan praktik seorang guru harus mampu menyampaikan materi yang dikuasainya, bagaimana mengontrol kelas, serta sejauh mana kemampuannya dalam menguasai peserta didik sesuai dengan salah satu kompetensi yang dituntut dari seorang pendidik yakni memiliki kemampuan pedagogik.

\section{Simpulan}

Penelitian ini telah berhasil mengungkap pertama, materi fiqih yang bersifat khilafiyah yaitu zakat barang tambang dan rikaz (barang temuan), nisab (jumlah minimal) barang yang dicuri, had (hukuman-hukuman) mencuri, had (hukumanhukuman) meminum khamar, had (hukuman-hukuman) perampok, penyamun dan perompak dan hukum asuransi dalam Islam, kedua, strategi pembelajaran guru fiqih dalam mengajarkan materi fiqih yang bersifat khilafiyah yaitu dengan menggunakan strategi pembelajaran langsung, ketiga, kendala yang dihadapi guru fiqih dalam 
mengajarkan materi fiqih yang bersifat khilafiyah guru kurang mampu membangun pemahaman para santri dalam memahami persoalan-persoalan khilafiyah fiqih, para santri memiliki tingkat kecerdasan yang berbeda-beda dalam memahami materi, sarana dan prasarana terkait media pembelajaran masih terbatas sehingga guru hanya bisa menerapkan strategi pembelajaran langsung dengan menggunakan metode ceramah. Bagi peneliti selanjutnya yang akan meneliti pada tema yang sama diharapkan dapat melakukan penelitian dengan judul yang lebih spesifik.

\section{Referensi}

Darmawiyah, D. (2017). Strategi Pembelajaran Fiqih Mawaris Pada Daya Madinatuddiniyah Darul Huda Aloh Gadeng Dan Dayah Terpadu Madinatuddiniyah Jabal Nur Paloh Lada Di Kabupaten Aceh Utara. Jurnal ilmiah didaktika. https://doi.org/10.22373/jid.v17i2.1642.

Fakhrurrazi, F. (2018). Hakikat Pembelajaran yang Efektif. At-tafkhir. https://doi.org/10.32505/at.v11i1.529.

Fatimah \& Sari, R.D.K. (2018). Strategi Pembelajaran \& Pembelajaran dalam Meningkatkan Keterampilan Bahasa. Pendidikan Bahasa dan Sastra Indonesia.

Gunawan, Imam. (2013). Metode Penelitian Kualitatif. Jakarta: Bumi Aksara.

Halimah, Nur, dkk. (2019). Strategi Guru dalam Meningkatkan Mutu Pembelajaran Fiqih Kelas 1 di Madrasah Ibtidaiyah Khadijah Malang. Jurnal Pendidikan Madrasah Ibtidaiyah Nomor 2 Tahun 19, 189-197.

Hasanah, H. (2017). Teknik-Teknik Observasi. At-Taqaddum.

Jamrah, S.A. (2014). Ikhtilaf dan Etika Perbedaan dalam Islam. Toleransi.

Maslihan. (2019). Pengertian Strategi Pembelajaran. Diperoleh dari https://ilmunik.com.

Nanang, Abdillah. (2016). Mazhab dan Faktor Penyebab Terjadinya Perbedaan. Jurnal Pendidikan dan Pendidikan Islam.

Nurdiani, N. (2014). Teknik Sampling Snowball dalam Penelitian Lapangan. ComTech: Computer, Mathematics and Engineering Applications. https://doi.org/10.21512/comtech.v5i2.2427

Nata, D. H. A. (2014). Perspektif Islam tentang strategi pembelajaran. Kencana.

Nasution, W.N. (2017). Perencanaan Pembelajaran, Pengertian, Tujuan dan Prosedur. Ittihad.

Nurhayati. (2018). Fiqih dan Ushul Fiqih. Kencana. Jakarta: Prenada Media Group.

Nilamsari, N. (2014). Memahami Studi Dokumen Dalam Penelitian Kualitatif. Wacana. 
Sardiyanah, S.. (2020). Belajar dan Faktor yang Mempengaruhinya. Jurnal AlQalam: Jurnal Kajian Islam \& Pendidikan. https://doi.org/10.47435/alIqalam.v7i1.187.

Sapuadi. (2019). Strategi Pembelajaran. Nurani Borneo. Medan: Harapan Cerdas.

Pane, A., \& Darwis Dasopang, M. (2017). Belajar dan Pembelajaran. Fitrah: Jurnal Kajian Ilmu-Ilmu Keislaman. https://doi.org/10.24952/fitrah.v3i2.945.

Wawancara bersama guru fiqih Bapak Khairul, BA Kamis 4 Februari 2021

Zahid, R. A. (2016). Sebab-Sebab Terjadinya Perbedaan Mazhab. Jurnal Pemikiran Keislaman. https://doi.org/10.33367/tribakti.v26i1.203.

Raco. (2010). Metode Penelitian Kualitatif. Jakarta: Grasindo.

Rijali, A. (2019). Analisis Data Kualitatif. Alhadharah: Jurnal Ilmu Dakwah. https://doi.org/10.18592/alhadharah.v17i33.2374. 